\title{
Unmarried male migrants and sexual risk behavior: a cross-sectional study in Shanghai, China
}

\author{
Ke-Wei Wang ${ }^{1,2}$, Jun-Qing $\mathrm{Wu}^{1,2^{*}}$, Hong-Xin Zhao ${ }^{4}$, Yu-Yan Li ${ }^{2}$, Rui Zhao ${ }^{2}$, Ying Zhou ${ }^{2,3}$ and Hong Lei $\mathrm{Ji}^{2}$
}

\begin{abstract}
Background: In China, there is increasing concern because of the rapid increase in HIV infection recorded over recent years. Migrant workers are recognized as one of the groups most affected. In this study, HIV/AIDS-related knowledge, attitudes, and behavior among unmarried migrant workers in Shanghai are investigated, with the aim of providing critical information for policy makers and sex educators to reinforce sexual health services and sex health education targeting the behavior and sexual health of unmarried male migrants.

Methods: A cross-sectional survey was conducted among unmarried male migrant workers in Shanghai, China's largest city and housing the most migrants. A self-administered, anonymous questionnaire was used to collect information on knowledge, attitudes, and behavior associated with increased risk of HIV/AIDS.

Results: A total of 2254 subjects were questioned, with a response rate of $91.3 \%$. Among those interviewed, $63.5 \%$ reported sexual activities. Misconceptions regarding HIV transmission, poor perception of HIV infection, and low use of condoms were not uncommon. Among those who had sexual intercourse, $73.7 \%$ had not used condoms in their last sexual intercourse, and 28.6\% reported having engaged in sexual risk behavior (defined as having at least one non-regular partner). Multivariate logistic regression analyses identified several indicators of sexual risk behavior, including younger age at first sexual intercourse (OR: $0.67,95 \% \mathrm{Cl}: 0.31-0.91$ for older age at first sexual intercourse), more cities of migration (OR: 2.91, 95\% Cl: 2.17-3.81 for high level; OR: 1.15, 95\% Cl: 1.06-1.29 for medium level), poor perception of acquiring HIV/AIDS (OR: 1.52, 95\% Cl: 1.33-1.96 for unlikely; OR: 2.38, 95\% Cl: 1.61-3.70 for impossible), frequent exposure to pornography (OR: 0.33, 95\% Cl: 0.11-0.43 for never; OR: 0.69, 95\% Cl: 0.60-1.81 for less frequently), not knowing someone who had or had died of HIV/AIDS and related diseases (OR: 2.13,95\% Cl: 1.70-2.53 for no), and having peers who engaged in sex with a non-regular sex partner (OR: 4.40, 95\% Cl: 3.37-5.56 for yes).
\end{abstract}

Conclusions: Today, it is necessary to reinforce sex health education among unmarried migrants and sexual health services should target vulnerable migrant young people.

\section{Background}

It is clear that China is facing a frightening epidemic of AIDS. By 2011, the official estimate of the total number of people infected with HIV was 650,000 [1]. Although the epidemic remains has been largely confined to high-risk groups, the virus has begun to spread to an increasing number of areas and populations, resulting

\footnotetext{
*Correspondence: wuja1688@163.com

'School of Public Health of Fudan University, 138 Dong An Road, Shanghai, P.R. China

${ }^{2}$ Department of Epidemiology and Social Science on Reproductive Health, Shanghai Institute of Planned Parenthood Research/WHO Collaborating Centre for Research in Human Reproduction Unit of Epidemiology, 2140 Xie Tu Road, Shanghai, P.R. China

Full list of author information is available at the end of the article
}

in the early phase of a likely the widespread dissemination of HIV to the general population [2]. At the same time, the mode of HIV transmission has shifted substantially over time. Sexual transmission has been the largest single cause of HIV infection in China, and heterosexual transmission has already become the main mode of transmission [1]. Rural-to-urban migration may be playing a crucial role in the rapid diffusion of HIV [3].

With China's fast industrialization and urbanization since the initiation of the "open door policy" in the 1970s, China has experienced rapid economic growth. Large economic disparities between urban and rural areas led to the emergence of rural-to-urban migration

\section{Biomed Central}

(C) 2013 Wang et al.; licensee BioMed Central Ltd. This is an Open Access article distributed under the terms of the Creative Commons Attribution License (http://creativecommons.org/licenses/by/2.0), which permits unrestricted use, distribution, and reproduction in any medium, provided the original work is properly cited. The Creative Commons Public Domain Dedication waiver (http://creativecommons.org/publicdomain/zero/1.0/) applies to the data made available in this article, unless otherwise stated. 
as villagers looked for new jobs, higher income and homes in towns and cities. There were an estimated 230 million migrant laborers in China by the end of 2011 [4].

Nearly half of China's migrants were born in the 1980 s, their average age being about 28 years old [4]. The majority of migrants have a poor educational background. Although most are in the sexually active stage of their lives, they actually possess little knowledge about HIV, sex health-related matters, or protection, and have almost no access to preventive education or regular health care. This all leads to a major concern about the health consequences of migration in China today: migrant workers are particularly vulnerable to sexual risk behavior, which in turn makes them more susceptible to HIV infection [2,5,6].

Most young migrants are rural-to-urban migrants, far from home and released from the restraints exerted by their parents; they are living in single-sex dormitory housing and working long hours in difficult conditions; and their attitudes about sexuality and lifestyles have changed since they immigrated [2,5]. It is assumed that under such circumstances, these migrants are more likely to engage in sexual risk behavior, like having casual sex and paying for sex and having multiple sexual partners [7-9]. Some studies have shown that migrant workers' knowledge of HIV/AIDS is minimal and that they are unable to obtain useful information, consultation, and healthcare services pertaining to HIV/AIDS $[10,11]$. Some researchers have found a relationship between sexual risk behavior and poor knowledge of HIV/ AIDS. Sexual behavior studies in China and other countries have shown that poor knowledge of HIV/AIDS increases the likelihood of engaging in sexual risk behavior $[12,13]$. Studies from other countries have shown that the sexual attitudes of young, mobile people become increasingly open and that they are particularly likely to indulge in HIV/AIDS-related sexual risk behavior [14-17]. Similar studies of migrant workers in China have indicated that premarital and extramarital sex appear to have become more accepted among young people $[18,19]$. Hesketh $[20]$ proposed that traditional attitudes to sexual relationships place migrant workers at low risk for engaging in casual sex. $\mathrm{Na} \mathrm{He}$ [21] stated demand for legalization of commercial sex increases the risk of having more than one sexual partner. Xun Zhuang [22] concluded that acceptance of multiple sex partners increases the risk of engaging in sexual risk behavior. In addition, the household registration system (the hukou) has restricted peasant entry into the cities to control unwanted migration out of the countryside. Therefore, most rural-to-urban migrants can only gain temporary status in the cities and have to travel back to the countryside periodically. Several studies have shown that migrants tend to be at a higher risk of contracting
HIV and other sexually transmitted diseases (STDs) than non-migrants $[23,24]$. A great many studies have indicated that HIV infected patients in China cities consist mostly of migrant workers [25-27]. Multiple sources have documented how migrants serve as a bridge population for the spread of HIV from migrant destinations back to native regions, with the frequent seasonal shifts between work in cities and return to homelands leading to the further transmission of HIV among their sex partners [28-30].

Previous investigations of migrants' HIV-related sexual behavior in China have largely focused on male migrants or migrant female sex workers [21,22,31]. Few studies have focused on sexual risk behavior in rural-to-urban unmarried male migrants. Unmarried males in particular may be likely to engage in HIV risk-taking behavior, much more so than married males because of their specific physiological and psychological characteristics in the context of exposure to HIV risk-taking factors in the urban environment [2,32]. For this study, therefore, we conducted a community-based, cross-sectional study of HIV-related risk behavior among unmarried male migrants in Shanghai, China's largest city with almost nine million migrants [33]. The objectives of the investigation were to describe the HIV/AIDS-related knowledge, attitudes, and risk behavior of and thus identify possible sexual risk behavior factors among unmarried male migrants in Shanghai.

\section{Methods}

Data

This study was conducted in Shanghai, the first largest and most highly migrant populated city of China. Located in the eastern part of the country, the city is administratively divided in to 16 administrative districts and one county. One (Xuhui district with 1.47 million people) of the districts, was randomly recruited, within which 12 communities were selected as sources of study participants.

A quota-sampling procedure was utilized to recruit a composite sample that was approximately proportionate to the overall distribution of the migrant population in 11 different occupational clusters (porter, operating a business stand, delivery man, decorator, installation worker, salesman, wholesale and retail trade, security guard, construction, manufacturing, and waiter) accounting for approximately $93 \%$ of the migrants. The scene investigation was administered during April and May 2012, with a final total of 2468 unmarried male participants volunteering to participate in the study after their informed consent had been obtained. Inclusion criteria for eligible participants were as follows: (1) Men; (2) Unmarried; (3) Not registered as a permanent resident of Shanghai; (4) Had resided in the current city for at least half a year. 
The questionnaire for this study was designed mainly on the basis of the scales used in China's National HIV Surveillance Surveys, and information was gathered from several group discussions with migrant workers. The measures used were in accord with others employed in other studies in China of knowledge/awareness about HIV/AIDS $[21,22,34]$. The feedback from group discussions suggested that the majority of migrant workers would respond more honestly about their sexual activities with an anonymous questionnaire. The questionnaire covered three main areas: The first part included less sensitive questions, such as the demographic characteristics of the migrant workers, peer influence, exposure to pornography, and acquaintance with someone who had or had died of HIV/AIDS and related diseases. The second part included their knowledge of and attitudes to HIV/AIDS. The third part consisted of questions regarding the respondents' sexual activities and use of condoms.

\section{Measures \\ Socio-demographics}

We included several socio-demographic characteristics: age (years), ethnicity, educational attainment, monthly income (dollars), number of cities of migration, age at first sexual intercourse, type of city housing, risk perception of acquiring HIV/AIDS, exposure to pornography, HIV/AIDS-related knowledge, whether non-regular sex should be acceptable, whether permissive regarding premarital sex, whether condom use could prevent HIV/ AIDS, whether or not knew someone who had or had died of HIV/AIDS and related diseases, and whether or not have peers who had engaged in sex with a nonregular sex partner. In this study migrants' peers only refer to friends and workmates around. Age was grouped into 4 categories: $<15,15-19,20-24$, and 25 years or older. Education was analyzed in terms of the following categories: elementary school or lower, junior high school, and high school or above. Ethnicity was grouped into Han and other. Monthly income (dollars) was grouped into 4 categories: <161.5, 161.6-322.9, 323.0484.5 , and 484.6 dollars or more. The number of cities of migration was stratified into 1,2 and 3 or more. Age at first sexual intercourse was grouped into two bands: $<22$ and 22 years or older. The housing type/place of residence was divided into 5 categories: collective dormitory with others, own room in a dormitory, room with parents, rented room, and other. Exposure to pornography was categorized into 3 groups: frequent $(\geq 3$ times every 6 months), less frequent ( $<3$ times every 6 months), and never. Peer influence was classified according to whether or not the migrant had peers who engaged in sex with a non-regular sex partner.

\section{HIV/AIDS-related knowledge and attitudes}

HIV/AIDS knowledge-the subscale score for HIV/AIDS knowledge (range 0-10) - was created by calculating the correct responses to ten items covering modes of transmission and protection information. Correct answers were credited with a score of one and incorrect answer with a score of zero, higher scores thus indicating a higher level of knowledge. The internal consistency of the subscale was 0.81. A summary score was developed from the ten HIV knowledge questions (three questions were about the three transmission modes of HIV, five on misconceptions about HIV transmission, one on whether regular use of antibiotics could prevent HIV/AIDS, and one on whether HIV/AIDS was curable). Participant's attitude toward sexual behavior was evaluated by three items, namely, their agreement with the following statements: (1) "It is permissible for people to have premarital sex," (2) "Casual sex should be acceptable," and (3) "Do you think you are at risk of HIV infection?" (with the answer options "very possible," "unlikely" and "impossible"). For condom knowledge and attitude, subjects were asked whether they regarded condom use as a good contraceptive measure and if they thought condom use could effectively prevent HIV/AIDS. Response options were either Yes or No.

\section{Sexual behavior and condom use}

Sexual risk behavior was defined as sex (heterosexuality by vagina) with a non-regular partner (casual or commercial sex partner) during the six months prior to the survey. Casual sex was defined as having sexual contact, without pay, with another person with no plans for a further long term/committed relationship with that person. Sexual behavior was assessed by questions regarding: (1) the relationships of sexual partners in the six months before the survey, and (2) condom use with sexual partners during the last sexual intercourse (yes/no). The outcome variables analyzed were four categorical variables related to the relationships with sexual partners: friends, living together, commercial sexual partners and casual partners. Casual and commercial sex partners were defined as non-regular, with friends and people they lived with coded as regular partner.

\section{Interviews}

Eligible individuals were asked to complete a selfadministered questionnaire in an isolated room or a quiet place to minimize embarrassment related to discussion of sensitive topics. Reading assistance was provided to participants with limited literacy. The study protocol was approved by the Ethics Committee of Fudan University School of Medicine. All study participants gave written consent before participation and all information was collected confidentially. 


\section{Data analysis}

Data on all the questionnaires were entered twice by different professionals using EpiData 3.1 to enable a comparison between the data and the correction of data entry mistakes. Data cleaning included consistency verification for all variables. The analysis was done using SAS version 9.2 (SAS Inc. Cary, NC, USA). Descriptive statistics included mean, frequencies, and proportions. HIV/AIDS-related knowledge was used as the continuous variable and entered with other independent variables with a statistical significance of $<0.10$ in the univariate analyses into the logistic regression model. Non-regular sexual intercourse (yes/no) was used as the dependent variable. The variables were then removed from the equation one at a time using stepwise backward elimination until the removal did not lead to a significant decrease in the strength of the equation. Pearson correlation coefficients were $<0.30$ for all bivariate relationships tested for the independent variables. No colinearity was found between the independent variables. Odds ratios (OR) were used as indictors of the strength of association. $P<0.05$ was considered statistically significant.

\section{Results}

\section{Characteristics of participants}

Of the total of 2468 migrants approached to participate in the survey, $214(8.7 \%)$ declined or were excluded because they did not provide information on sexual behavior, leaving a final sample of 2254. Of these, $65.3 \%$ reported sex experiences; over three-quarters (77.2\%) were 15-24 years old, and the majority (96.1\%) of Han ethnicity. Most (90.0\%) had completed junior high school or above. Nearly half $(46.6 \%)$ of the respondents reported that they had only migrated to one city. More four-fifths $(83.9 \%)$ of the participants reported that their monthly income was less than 484.6 dollars, with the average monthly income at 303.9 dollars. Approximately two-fifths (38.5\%) of respondents lived in a shared dormitory, $30.1 \%$ of the respondents had their own room in a dormitory, and $6.0 \%$ of the respondents lived in a rented room (Table 1 ).

\section{Knowledge of and attitudes to HIV/AIDS}

Most participants (73.5\%-83.0\%) could correctly identify the three major modes of HIV transmission, but many had substantial misconceptions regarding HIV transmission (data not shown). For example, nearly three-fifths (57.2\%) thought that HIV can be contracted through mosquito bites, and one-third (34.2\%) thought that it could be transmitted by eating with an HIV-positive person (data not shown).

Over four-fifths $(80.6 \%)$ of participants agreed with the statement "It is permissible for people to have premarital sex," and two-fifths (40.1\%) agreed that "non-regular sex
Table 1 Demographic characteristics of study participants and HIV/AIDS-related knowledge and attitudes among study participants

\begin{tabular}{lcc}
\hline Variable & $\mathbf{N}=\mathbf{2 2 5 4}$ & \% \\
\hline Sex experience & 1472 & 65.3 \\
Yes & 782 & 34.7 \\
No & & \\
Age (years) & 36 & 1.6 \\
$<15$ & 561 & 24.9 \\
$15-19$ & 1143 & 50.7 \\
$20-24$ & 514 & 22.8 \\
$\geq 25$ & & \\
Ethnicity & 2165 & 96.1 \\
Han & 89 & 3.9
\end{tabular}

Educational attainment

$\begin{array}{lll}\text { Elementary school or lower } & 230 & 10.0\end{array}$

Junior high school $\quad 1192 \quad 52.3$

$\begin{array}{lll}\text { High school or above } & 832 & 37.7\end{array}$

Number of cities of migration

11055

46.6

2

31.2

$\geq 3$

Monthly income (dollars)

$<161.5 \quad 394$

17.1

$161.6-322.9$

35.7

$323.0-484.5$

31.1

$\geq 484.6$

16.1

Type of city housing

$\begin{array}{lll}\text { Collective dormitory with others } & 878 & 38.5\end{array}$

$\begin{array}{lll}\text { Own room in a dormitory } & 670 & 30.1\end{array}$

Room with parents $\quad 478 \quad 21.3$

$\begin{array}{lll}\text { Room rented } & 136 & 6.0\end{array}$

Other

$92 \quad 4.1$

HIV/AIDS-related knowledge (mean)

Whether permissive regarding premarital sex

Yes 1817

No

Whether non-regular sex should be acceptable

Yes

40.1

No

Risk perception of acquiring HIV/AIDS

Very possible

Unlikely

Impossible 
Table 1 Demographic characteristics of study participants and HIV/AIDS-related knowledge and attitudes among study participants (Continued)

\begin{tabular}{lcc}
\hline Whether non-regular sex should be acceptable & & \\
Yes & 904 & 40.1 \\
No & 1350 & 59.9 \\
Risk perception of acquiring HIV/AIDS & & \\
Very possible & 399 & 17.7 \\
Unlikely & 735 & 32.6 \\
Impossible & 1120 & 49.7 \\
\hline
\end{tabular}

should be acceptable in China." Half (50.3\%) perceived themselves to be at risk of HIV infection, while $49.7 \%$ of respondents felt that they would not be likely to contract HIV/AIDS in the future, including those engaging in sex with non-regular partners. Regarding condom knowledge, approximately three-quarters (73.9\%) of respondents regarded condom use as a good contraceptive measure, although only $43.0 \%$ knew that condom use could effectively prevent HIV/AIDS (Table 1).

\section{Sexual behavior among participants having sex}

Table 2 shows the percentage distribution of the respondents according to variables related to premarital sex. About half (46.9\%) of the respondents experienced sex

Table 2 Percentage distribution of respondents according to variables related to sex behaviors among participants having sex experience

\begin{tabular}{lcc}
\hline Variables & $\mathbf{N = 1 4 7 2}$ & \% \\
\hline Age of first sexual experience & & \\
$<22$ & 691 & 46.9 \\
$\geq 22$ & 781 & 53.1 \\
Number of sexual partners in one's lifetime & & \\
1 & 937 & 63.7 \\
$\geq 2$ & 535 & 36.3 \\
The relationships of sexual partners & & \\
Regular partner (friends and living together) & 1050 & 71.4 \\
Non-regular partner (commercial sexual & 422 & 28.6 \\
partners and casual partners) & & \\
Condom use in the last sexual intercourse & & \\
Yes & 387 & 26.3 \\
No & 1085 & 73.7 \\
Oral Sexual intercourse & & \\
Yes & 98 & 6.7 \\
No & 1374 & 93.3 \\
Anal sexual intercourse & & \\
Yes & 10 & 0.68 \\
No & 1462 & 99.32 \\
\hline
\end{tabular}

before their 22th birthday, and the mean age at first sexual intercourse was 22.3 years. Almost two-thirds (63.7\%) of the sample reported having had only one sexual partner. Over a quarter $(28.6 \%)$ of participants reported having had non-regular (commercial and casual) sex in the last six months. Only $26.3 \%(n=387)$ of the participants had used condoms in their last sexual intercourse, meaning that $73.7 \%(n=1085)$ did not. Of the respondents who had engaged in sexual risk behavior, just 33.9\% $(n=143)$ reported condom use in their last sexual intercourse, meaning that $66.1 \%(n=279)$ did not (data not shown). About 6.7\% $(n=98)$ reported having had oral sexual intercourse, and ten $(0.68 \%)$ participants reported anal sexual intercourse with their partners.

\section{Sexual risk behavior}

Among all participants, 422 (18.6\%) reported sexual intercourse with at least one non-regular partner in the six months preceding the survey (Table 3 ); and $28.6 \%$ of participants having sex experience reported having nonregular sex (Table 2). About 24.3\% $(n=358)$ of participants having sex experience reported having had sexual intercourse with commercial sex workers, but only $10.9 \%(n=160)$ reported engaging in casual sex (data not shown). Among participants having sex experience, the occurrence of sexual risk behavior increased significantly with age $(\mathrm{p}<0.0001)$, with $37.4 \%$ of men in the oldest age group ( $\geq 25$ year old) having had sex with a non-regular partner (Table 3). In univariate analyses, our primary outcome, sexual risk behavior, showed significant associations with age, educational levels, number of cities of migration, age at first sexual intercourse, type of city housing, risk perception of acquiring HIV/AIDS, exposure to pornography, whether non-regular sex should be acceptable, whether knew someone who had or had died of HIV/AIDS and related diseases, and whether had peers who had engaged in sex with a non-regular sex partner (Table 3).

All factors significant at $\mathrm{p}<0.10$ in the univariate analysis were included in the multiple logistic regression analysis. After controlling for potential confounding variables, these results indicated that having had nonregular sex was associated with earlier age at first sexual intercourse, more cities of migration, poor perception of acquiring HIV/AIDS, frequent exposure to pornography, not knowing someone who had or had died of HIV/ AIDS and related diseases, and having peers who had engaged in sex with a non-regular sex partner (Table 4). Respondents who were older $(>22)$ at first sex were less likely (37\%) to have a non-regular sexual partner than respondents who were younger $(<22)$ at first sexual intercourse. For all participants, number of cities of migration was positively associated with sexual risk behavior. Males who had migrated to three or more cities 
Table 3 Univariate analyses of factors associated with ever having had sex with a non-regular partner among participants having sex experience

\begin{tabular}{|c|c|c|c|c|c|c|}
\hline \multirow[t]{2}{*}{ Variable } & \multirow[t]{2}{*}{$N=1472$} & \multicolumn{2}{|c|}{ Risk sex } & \multirow[t]{2}{*}{$P$-value } & \multirow[t]{2}{*}{ OR } & \multirow[t]{2}{*}{ OR $(95 \% \mathrm{Cl}$} \\
\hline & & Yes & $\%$ & & & \\
\hline \multicolumn{7}{|l|}{ Age (years) } \\
\hline$<15$ & 2 & 0 & 0 & & & \\
\hline $15-19$ & 360 & 77 & 21.4 & $<0.0001$ & 1 & \\
\hline $20-24$ & 746 & 209 & 27.9 & & 1.42 & $0.91-1.93$ \\
\hline$\geq 25$ & 364 & 136 & 37.4 & & 2.19 & $1.58-2.70$ \\
\hline \multicolumn{7}{|l|}{ Educational attainment } \\
\hline Elementary school or lower & 115 & 42 & 36.5 & 0.023 & 1 & \\
\hline Junior high school & 778 & 202 & 25.8 & & 0.61 & $0.31-0.89$ \\
\hline High school or above & 579 & 178 & 30.7 & & 0.77 & $0.55-0.97$ \\
\hline \multicolumn{7}{|l|}{ Monthly income (dollars) } \\
\hline$<161.5$ & 107 & 32 & 29.9 & 0.99 & 1 & \\
\hline $161.6-322.9$ & 549 & 156 & 28.4 & & 0.93 & $0.81-1.07$ \\
\hline $323.0-484.5$ & 480 & 137 & 28.5 & & 0.94 & $0.85-1.04$ \\
\hline$\geq 484.6$ & 336 & 96 & 28.5 & & 0.94 & $0.83-1.06$ \\
\hline \multicolumn{7}{|l|}{ Number of cities of migration } \\
\hline 1 & 688 & 173 & 25.0 & 0.015 & 1 & \\
\hline 2 & 448 & 140 & 31.3 & & 1.36 & $1.03-1.71$ \\
\hline$\geq 3$ & 336 & 109 & 32.4 & & 1.44 & $1.27-1.62$ \\
\hline \multicolumn{7}{|l|}{ Age at first sexual intercourse } \\
\hline$<22$ & 691 & 232 & 460 & $<0.0001$ & 1 & \\
\hline$\geq 22$ & 781 & 190 & 591 & & 0.64 & $0.51-0.81$ \\
\hline \multicolumn{7}{|l|}{ Type of city housing } \\
\hline Collective dormitory with others & 573 & 140 & 24.4 & $<0.0001$ & 1 & \\
\hline Own room in a dormitory & 417 & 148 & 35.2 & & 1.68 & $1.27-2.13$ \\
\hline Room with parents & 333 & 104 & 31.2 & & 1.41 & $1.08-1.77$ \\
\hline Room rented & 99 & 22 & 22.2 & & 0.88 & $0.78-0.97$ \\
\hline Other & 50 & 8 & 16 & & 0.59 & $0.45-0.71$ \\
\hline \multicolumn{7}{|c|}{ Risk perception of acquiring HIV/AIDS } \\
\hline Very possible & 428 & 66 & 15.4 & $<0.0001$ & 1 & \\
\hline Unlikely & 542 & 158 & 29.2 & & 2.25 & $1.78-2.75$ \\
\hline Impossible & 502 & 198 & 39.3 & & 3.54 & $2.91-4.17$ \\
\hline \multicolumn{7}{|l|}{ Exposure to pornography } \\
\hline Frequently & 672 & 229 & 34.1 & $<0.0001$ & 1 & \\
\hline Less frequently & 716 & 175 & 24.3 & & 0.62 & $0.38-0.88$ \\
\hline Never & 84 & 18 & 21.4 & & 0.53 & $0.31-0.76$ \\
\hline \multicolumn{7}{|c|}{ Whether permissive regarding premarital sex } \\
\hline Yes & 1177 & 329 & 27.9 & 0.21 & 1 & \\
\hline No & 295 & 93 & 31.5 & & 1.19 & $0.90-1.57$ \\
\hline \multicolumn{7}{|c|}{ Whether non-regular sex should be acceptable } \\
\hline Yes & 560 & 179 & 31.9 & 0.028 & 1 & \\
\hline No & 912 & 243 & 26.6 & & 0.77 & $0.61-0.97$ \\
\hline
\end{tabular}


Table 3 Univariate analyses of factors associated with ever having had sex with a non-regular partner among participants having sex experience (Continued)

Whether condom use could prevent HIV/AIDS

Yes

No

Whether or not knew someone who had or had died of HIV/AIDS and related diseases

Yes

No

Whether or not have peers who had engaged in sex with a non-regular sex partner

No

Yes
553

919

397

1075
171

251

30.9

27.3

69

353

17.4
32.8

0.138

0.84

$<0.0001$

2.32

$1.74-3.10$

$0.67-1.06$

748

724

$\begin{array}{ll}196 & 26.2 \\ 226 & 312\end{array}$

0.034

1

1.28

$1.02-1.60$

were 2.91 times more likely to engage in risky sexual intercourse than those having migrated to only one city. We also found a significant inverse relationship between risk perception and sexual risk behavior. This result suggests that respondents who perceive themselves to be only at low (unlikely and impossible) risk were significantly

Table 4 Logistic regression analysis of factors correlated with ever having had sex with non-regular sex partner

\begin{tabular}{|c|c|c|c|}
\hline Variable & OR & OR $(95 \% \mathrm{CI})$ & P-value \\
\hline \multicolumn{4}{|l|}{ Age at first sex } \\
\hline$<22$ & 1 & & 0.035 \\
\hline$\geq 22$ & 0.67 & $(0.31,0.91)$ & \\
\hline \multicolumn{4}{|c|}{ Number of cities of migration } \\
\hline 1 & 1 & & 0.028 \\
\hline 2 & 1.15 & $(1.06,1,29)$ & \\
\hline$\geq 3$ & 2.91 & $(2.17,3.81)$ & \\
\hline \multicolumn{4}{|c|}{ Risk perception of acquiring HIV/AIDS } \\
\hline Very possible & 1 & & $<0.0001$ \\
\hline Unlikely & 1.52 & $(1.33,1.96)$ & \\
\hline Impossible & 2.38 & $(1.61,3.70)$ & \\
\hline \multicolumn{4}{|c|}{ Exposure to pornography } \\
\hline Frequently & 1 & & 0.007 \\
\hline Less frequently & 0.69 & $(0.60,0.81)$ & \\
\hline Never & 0.33 & $(0.11,0.43)$ & \\
\hline \multicolumn{4}{|c|}{$\begin{array}{l}\text { Whether or not knew someone who } \\
\text { had or had died of HIV/AIDS and } \\
\text { related diseases }\end{array}$} \\
\hline Yes & 1 & & 0.012 \\
\hline No & 2.13 & $(1.70-2.53)$ & \\
\hline \multicolumn{4}{|c|}{$\begin{array}{l}\text { Whether or not have peers who had } \\
\text { engaged in sex with a non-regular } \\
\text { sex partner }\end{array}$} \\
\hline No & 1 & & $<0.0001$ \\
\hline Yes & 4.40 & $(3.37-5.56)$ & \\
\hline
\end{tabular}

more likely $(\mathrm{OR}=1.52$ and $\mathrm{OR}=2.38$, respectively) to take part in sexual risk behavior. Compared to those who frequently viewed pornography, respondents who were never or less frequently exposed to pornography were less likely to report sexual risk behavior (67\% and $31 \%$, respectively). Knowing someone who had or had died of HIV/AIDS and related diseases demonstrated a strong protective association with sexual risk behavior. Respondents who had never known people with these diseases were 2.13 times more likely to engage in sexual risk behavior than were those who had known such people. Finally, respondents who had peers engaging in sex with a non-regular sex partner were 4.4 times more likely to be involved in sexual risk behavior than were those who did not engage thus.

\section{Discussion}

To our knowledge, this study is the first in China to document sexual risk behavior and attempt to assess the likely causal factors for sexual risk behavior among unmarried male migrants.

We found a high proportion of male migrants having sexual intercourse before marriage, which may still represent an underreporting due to the sensitive nature of the issue and strong social and cultural taboos related to this area in China [35]. At the same time, the prevalence of sexual risk behavior (defined as sex with a nonregular sex partner) among single men revealed by this data is much higher than the levels observed by Xun Zhuang et al [22]. This may be because the latter study was based on the general population rather than focusing on an unmarried group. In addition, among young unmarried men interviewed in this survey, the rate of sexual risk behavior increased significantly with age. This means older respondents were more likely than younger ones to have non-regular sexual relationships. One of the main reasons could be that sexually active unmarried men in general engaged in sexual risk behavior in order 
to meet physical needs and relieve their loneliness and anxieties about home [2].

Of the participants engaging in premarital sex in our sample, $36.3 \%$ reported having had more than one sexual partner in their life, a proportion significantly higher than that reported by another study [21]. This finding is important because it enhances our understanding of the possible effects of multiple sex partners as increasing the likelihood of rapid transmission of HIV/AIDS. If someone has acquired HIV/AIDS, he may infect other partners, so not only are a large proportion of unmarried men at high risk of infections (those with multiple sex partners), but their partners are also likely to be at risk [36].

The study also showed that only about $43.0 \%$ of all migrants believed that use of condoms could prevent HIV/ AIDS, and infrequent condom use, another high-sexual risk behavior, was common among the males who had had sex in the six months before the study period. Nearly three-quarters (73.7\%) of respondents did not use a condom. More importantly, condom use was also quite low among the migrants who engaged in sexual risk behavior. A considerable proportion (66.1\%) of the male migrants also did not use a condom in their last sexual intercourse. These results show that sexually active individuals do not routinely practice safe sex, leading to a high risk of HIV infection. The low rate of condom use may explain their poor knowledge about the protective effects of condoms against HIV [37]. The findings indicate that the government needs to pay more attention to interventions targeting unmarried male migrants that could be effective in improving their awareness of condom use. For example, community interventions, including lec-tubes (experts lecture), posters, brochures, and videos, could be used to help them think of condoms as a cost-effective approach to sexually transmitted diseases/HIV prevention and contraception.

Despite a majority of participants having heard of AIDS and knowing the major routes of HIV transmission, many had substantial misconceptions regarding other routes. This report is similar to reports by authorities citing knowledge of mode of transmission of HIV/ AIDS among Nepalese migrants in India [9]. Here, about half of respondents did not perceive themselves to be at risk of HIV infection: also, respondents largely considered premarital sex to be acceptable. In our study, this phenomenon of risk behavior and perception of HIV/ AIDS, which indicates a risk of HIV infection, highlights the need for the promotion of safer sex among migrants.

These study findings have important implications for developing HIV intervention programs targeting migrants in Shanghai. First, we found that, consistent with an earlier study [22], males that have first sexual intercourse at a younger age were more likely to report having non-regular sex partners in the previous six months, suggesting the importance of focusing on HIV prevention interventions on younger, sexually experienced males. Second, a noteworthy finding in this study was the strong association of sexual risk behavior with exposure to pornography. Those who were exposed to pornography were more likely to engage in risk behavior than those who were not. This suggests that more intense efforts should be made to improve awareness about the seriousness of exposure to pornography among unmarried males and help them to develop a proper attitude to it. Third, another noteworthy finding was that having peers who had engaged in sex with a non-regular sex partner increased the likelihood of the involvement of unmarried males in risky sexual encounters. Studies conducted in the U.S. have demonstrated that social network members can influence the behaviors of others through a variety of mechanisms, including social comparisons, social control processes, and fear of social sanctions [38,39]. In common with other types of human behavior, our results demonstrate that peers may exert a significant influence on the sexual risk behavior of individuals. The results are also in line with those of another study, which found that the social influence of peers contributes to increased sexual risk behavior among migrants [40]. The findings imply that HIV intervention programs not only focus on individual risk takers but also on their broader social network of peers. Fourth, our analysis revealed that the number of cities to which men migrated was positively associated with higher risk sex and that participants who had a history of moving to more cities of migration were more likely to report higher risk sex. Unique HIV prevention and intervention strategies should be conducted in this population. Fifth, as expected, participants who perceived themselves to be at low risk of HIV infection were more likely to report non-regular sexual partners than those having a higher risk perception. Despite many achievements in HIV knowledge dissemination, there remains an essential need to educate migrants more extensively about HIV/ AIDS prevention and transmission, and to increase personal skills in protection against HIV infection. Sixth, we found the strong protective association with sexual risk behavior of knowing someone who had or had died of HIV/AIDS and related diseases. This finding was similar to the results of a study conducted among the young in the United States [41]. Interventions need to address ways to help migrants better understand the serious consequences of sexual risk behavior, including various infectious diseases and especially HIV/AIDS. Seventh, our study also showed that many migrants had substantial misconceptions regarding HIV transmission. Therefore, interventions to improve HIV/AIDS-related knowledge need to focus on unmarried male migrants, particularly those engaging in risky behaviors and emphasize the ways HIV is not transmitted in addition to the major routes of 
HIV transmission. Finally, more intervention programs should target migrants, especially young unmarried males, and condom use should be emphasized strongly, targeting also non-regular sex partners.

\section{Conclusions}

To our knowledge, this study is the first in China to focus on unmarried male migrants, an understudied subgroup with a potentially greater risk of contracting HIV in China. Our study not only described HIV/AIDSrelated knowledge, attitudes, and sexual risk behavior in this subgroup but also identified possible sexual risk behavior factors, such as earlier age at first sexual intercourse, more cities of migration, poor perception of acquiring HIV/AIDS, frequent exposure to pornography, not knowing someone who had or had died of HIV/ AIDS and related diseases, and having peers who had engaged in sex with a non-regular sex partner. The results provide critical information for policy makers and sex educators to reinforce sexual health services and sex health education targeting the behavior and sexual health of unmarried male migrants.

\section{Limitations}

This study has also several limitations. First, this was a cross-sectional survey, limiting our ability to draw causal inferences. Second, all variables were self-reported. Respondents may have underreported sexual risk behavior because sex is a sensitive topic in China. Third, due to the cross-sectional nature of the data, most responses were measured retrospectively, and recall bias might have occurred. Last, our sampling was limited to only a single city. We cannot, therefore, claim that our findings are representative for all unmarried male migrants in China-but the results do provide useful insights and suggest possible interventions to address sexual health risks for migrants.

\section{Competing interests}

There is no conflict of interest and the authors alone are responsible for the content and writing of the paper.

\section{Authors' contributions}

KWW performed the statistical analysis, involved in interpretation of the results and drafted the manuscript. WQW, HXZ, YYL and RZ conceived of the study and participated in the design of the study. $Y Z$ and HLJ participated in its design and coordination and helped to draft the manuscript. All authors read and approved the final manuscript.

\section{Acknowledgments}

We are grateful to our other project investigators, including interviewers and the study participants who received the study team with understanding and patience. This project was funded by the National 12th Five-Year Plan (No. 2012BAI32B08) and Xuhui District Scientific Technology Commission (No. YZ11-35-1)

\section{Author details}

${ }^{1}$ School of Public Health of Fudan University, 138 Dong An Road, Shanghai, P.R. China. ${ }^{2}$ Department of Epidemiology and Social Science on Reproductive
Health, Shanghai Institute of Planned Parenthood Research/WHO Collaborating Centre for Research in Human Reproduction Unit of Epidemiology, 2140 Xie Tu Road, Shanghai, P.R. China. ${ }^{3}$ The Key Laboratory of Family Planning Device of National Population and Family Planning Commission, 2140 Xie Tu Road, Shanghai, P.R. China. ${ }^{4}$ Ge Lan Su Shi Ke Company, Shanghai, P.R. China.

Received: 22 September 2013 Accepted: 5 December 2013 Published: 9 December 2013

\section{References}

1. $\mathrm{CMOH}$, UNAIDS, \& WHO: Update on the HIV/STD Epidemic and Response in China 2011. Beijing: China Ministry of Health; 2012.

2. Wolffers I, Fernandez I, Verghis S, Vink M: Sexual behaviour and vulnerability of migrant workers for HIV infection. Cult Health Sex 2002, 4(4):459-473.

3. Hong Y, Stanton B, Li X, Yang H, Lin D, Fang X, Wang J, Mao R: Rural-to-urban migrants and the HIV epidemic in China. AIDS Behav 2006, 10(4):421-430.

4. National Bureau of Statistics of China: Statistics of the Sixth National Census in 2012. Bejing: National Bureau of Statistics of China; 2012. http://www.ce. cn/macro/more/201201/18/t20120118_23009813.shtml.

5. Zhu TF, Wang $\mathrm{CH}$, Lin $\mathrm{P}, \mathrm{He} \mathrm{N}$ : High risk populations and HIV-1 infection in China. Cell Res 2005, 15(11-12):852-857.

6. Greener R, Sarkar S: Risk and vulnerability: do socioeconomic factors influence the risk of acquiring HIV in Asia? Aids 2010, 24(Suppl 3):S3-S11.

7. Akin M, Fernandez MI, Bowen GS, Warren JC: HIV risk behaviors of Latin American and Caribbean men who have sex with men in Miami, Florida, USA. Rev Panam Salud Publica 2008, 23(5):341-348.

8. Hoffman S, Higgins JA, Beckford-Jarrett ST, Augenbraun M, Bylander KE, Mantell JE, Wilson TE: Contexts of risk and networks of protection: NYC West Indian immigrants' perceptions of migration and vulnerability to sexually transmitted diseases. Cult Health Sex 2011, 13(5):513-528

9. Poudel KC, Okumura J, Sherchand JB, Jimba M, Murakami I, Wakai S: Mumbai disease in far western Nepal: HIV infection and syphilis among male migrant-returnees and non-migrants. Trop Med Int Health 2003, 8(10):933-939.

10. Owoaje ET, Adebiyi AO, Adebayo MA: Sexual risk behaviours and HIV knowledge of migrant farm workers in a rural community in Nigeria. Afr J Med Med Sci 2011, 40(1):75-84.

11. Lagarde E, Pison G, Enel C: Knowledge, attitudes and perception of AIDS in rural Senegal: relationship to sexual behaviour and behaviour change. Aids 1996, 10(3):327-334.

12. Vian T, Semrau K, Hamer DH, Loan LT, Sabin LL: HIV/AIDS-related knowledge and behaviors among most-at-risk populations in Vietnam. Open AIDS J 2012, 6:259-265.

13. Hesketh T, Zhang J, Qiang DJ: HIV knowledge and risk behaviour of female sex workers in Yunnan Province, China: potential as bridging groups to the general population. AIDS Care 2005, 17(8):958-966.

14. Waszak GC, Wedderburn M, McCarraher D, Cuthbertson C, Pottinger A Sexual violence and reproductive health among young people in three communities in Jamaica. J Interpers Violence 2006, 21(11):1512-1533.

15. Kiene SM, Subramanian SV: Event-level association between alcohol use and unprotected sex during last sex: evidence from population-based surveys in sub-Saharan Africa. BMC Public Health 2013, 13:583.

16. Amin S, Diamond I, Naved RT, Newby M: Transition to adulthood of female garment-factory workers in Bangladesh. Stud Fam Plann 1998, 29(2):185-200

17. Puri M, Cleland J: Sexual behavior and perceived risk of HIV/AIDS among young migrant factory workers in Nepal. J Adolescent Health 2006, 38(3):237-246

18. Liu HJ, Xie J, Yu WZ, Song WS, Gao ZY, Ma ZX, Detels R: A study of sexual behavior among rural residents of China. J Acquir Immune Defic Syndr Hum Retrovirol 1998, 19(1):80-88.

19. Li SH, Huang H, Cai Y, Xu G, Huang FR, Shen XM: Characteristics and determinants of sexual behavior among adolescents of migrant workers in Shangai (China). BMC Public Health 2009, 9(195). http://www. biomedcentral.com/1471-2458/9/195.

20. Hesketh T, Li L, Ye X, Wang H, Jiang M, Tomkins A: HIV and syphilis in migrant workers in eastern China. Sex Transm Infect 2006, 82(1):11-14. 
21. He N, Detels R, Chen Z, Jiang Q, Zhu J, Dai Y, Wu M, Zhong X, Fu C, Gui D: Sexual behavior among employed male rural migrants in Shanghai, China. AIDS Educ Prev 2006, 18(2):176-186.

22. Zhuang X, Wu Z, Poundstone K, Yang C, Zhong Y, Jiang S: HIV-related high-risk behaviors among Chinese migrant construction laborers in Nantong, Jiangsu. PLoS One 2012, 7(3):e31986.

23. Nunn AJ, Wagner HU, Kamali A, Kengeya-Kayondo JF, Mulder DW: Migration and HIV-1 seroprevalence in a rural Ugandan population. Aids 1995, 9(5):503-506

24. Lurie MN, Williams BG, Zuma K, Mkaya-Mwamburi D, Garnett G, Sturm AW, Sweat MD, Gittelsohn J, Abdool KS: The impact of migration on HIV-1 transmission in South Africa: a study of migrant and nonmigrant men and their partners. Sex Transm Dis 2003, 30(2):149-156.

25. Zhang YJ, Wang JH, Ni HN: Prevalence of HIV infection among floating population in Xianju County, Zhejiang Province. Zhejiang J Prev Med 2008, 20:25 (in Chinese).

26. Zhou ZM, Yu XH, Wang JH, et al: Epidemic characteristics of HIV infection of floating population in Wenzhou. Dis Surveill 2003, 18:123-125 (in Chinese).

27. Wang WJ: Analysis on the status, issues and trend on AIDS prevention and control among the mobile population. Chin J Epidemiol 2009, 30:407-409 (in Chinese).

28. Qian HZ, Vermund SH, Wang N: Risk of HIV/AIDS in China: subpopulations of special importance. Sex Transm Infect 2005, 81(6):442-447.

29. Anderson AF, Qingsi Z, Hua X, Jianfeng B: China's floating population and the potential for HIV transmission: a social-behavioural perspective. AIDS Care 2003, 15(2):177-185.

30. Lau JT, Thomas J: Risk behaviours of Hong Kong male residents travelling to mainland China: a potential bridge population for HIV infection. AIDS Care 2001, 13(1):71-81.

31. Ye X, Shang M, Shen T, Pei B, Jiang X, Cai Y: Social, psychological, and environmental-structural factors determine consistent condom use among rural-to-urban migrant female sex workers in Shanghai China. BMC Public Health 2012, 12:599.

32. He N: Sociodemographic characteristics, sexual behavior, and HIV risks of rural-to-urban migrants in China. Biosci Trends 2007, 1(2):72-80.

33. Shanghai Municipal Bureau of Statistics: Shanghai's sixth national census (2011). 2011. http://www.shanghai.gov.cn/shanghai/node2314/index.html.

34. National Center for AIDS/STD Control and Prevention of China CDC: National HIV Surveillance Survey Reference. Beijing: China CDC; 2009.

35. Gao E, Lou C, Liu Y: Assessment on accuracy of the data concerning first sexual behavior in Shanghai, China. Reprod Contracept 2003, 3:421-435

36. Sayles JN, Pettifor A, Wong MD, MacPhail C, Lee SJ, Hendriksen E, Rees HV, Coates T: Factors associated with self-efficacy for condom use and sexual negotiation among South african youth. J Acquir Immune Defic Syndr 2006, 43(2):226-233.

37. Adrien A, Cayemittes M, Bergevin Y: AIDS-related knowledge, attitudes, beliefs, and practices in Haiti. Bull Pan Am Health Organ 1993, 27(3):234-243

38. Fisher JD: Possible effects of reference group-based social influence on AIDS-risk behavior and AIDS prevention. Am Psychol 1988, 43(11):914-920.

39. Hall A, Wellman B: Social Networks and Social Support, in Social Support and Health Eds S Cohen, L Syme. New York: Academic Press; 1985:23-41.

40. Yang $X$ : Temporary migration and HIV risk behaviors in China. Environ Plan A 2006, 38(8):1527-1543.

41. Martino SC, Collins RL, Elliott MN, Strachman A, Kanouse DE, Berry SH: Exposure to degrading versus nondegrading music lyrics and sexual behavior among youth. Pediatrics 2006, 118(2):e430-e441.

doi:10.1186/1471-2458-13-1152

Cite this article as: Wang et al:: Unmarried male migrants and sexual risk behavior: a cross-sectional study in Shanghai, China. BMC Public Health 2013 13:1152

\section{Submit your next manuscript to BioMed Central and take full advantage of:}

- Convenient online submission

- Thorough peer review

- No space constraints or color figure charges

- Immediate publication on acceptance

- Inclusion in PubMed, CAS, Scopus and Google Scholar

- Research which is freely available for redistribution 